\title{
Biomedical Uses of Sulfobetaine-Based Zwitterionic Materials
}

\author{
Francesco Zaccarian ${ }^{\mathrm{a}, \mathrm{b}}$ (D) \\ Matthew B. Baker*b (iD) \\ Matthew J. Webber*a (iD) \\ ${ }^{a}$ Chemical \& Biomolecular Engineering Department, University of Notre Dame, Notre \\ Dame, IN 46556, United States \\ b Department of Complex Tissue Regeneration, MERLN Institute for Technology \\ Inspired Regenerative Medicine, Maastricht University, 6211 LK, Maastricht, \\ The Netherlands \\ m.baker@maastrichtuniversity.nl; mwebber@nd.edu
}

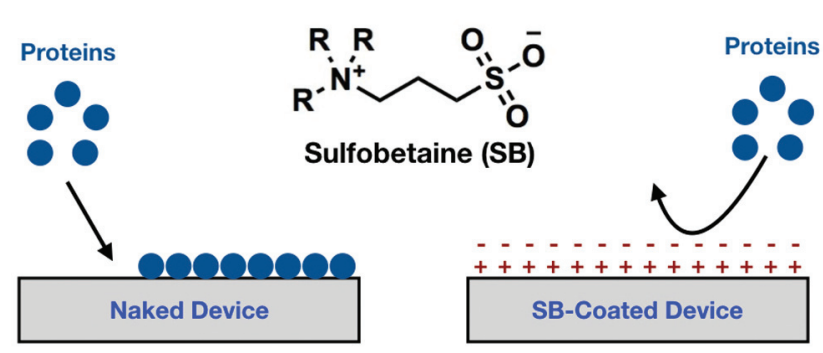

practice of medicine, including through the augmentation of damaged or defective tissues, the localized or systemic delivery of therapeutics, or the real-time monitoring and/or control of physiological systems. ${ }^{5}$ In spite of significant impact, there still remain challenges to the implementation of biomaterials in medicine which must be overcome. Among the most pressing of the challenges is the foreign body reaction. ${ }^{6}$ The immune response to a foreign material is an important component of innate immunity in order to maintain health in the face of infectious pathogens, yet can prove detrimental to the function of an implanted biomaterial. The canonical foreign body reaction follows a cascade of events (Figure 1). ${ }^{7}$ The foreign body reaction typically begins with the spontaneous adsorption of endogenous proteins to the surface of the implanted material. ${ }^{8,9}$ For many applications, fibrinogen is among the proteins to first adhere and be activated, resulting in a conditioned surface for further adhesion of platelets and neutrophils. ${ }^{10}$ Surface-activated neutrophils secrete cytokines and reactive oxygen species, and over subsequent days recruit monocytes and macrophages to participate in the reaction against the material. Macrophages work to clear smaller foreign bodies, but also secrete their own signaling molecules to recruit fibroblasts to build collagen-rich fibrotic scar tissue around the implant. ${ }^{6,11}$ This dense fibrotic capsule can prove detrimental to device function and integration into host tissue. For example, it may impose mass transport limitations for applications involving the release of drugs or related payloads or starve cells embedded within the biomaterial of oxygen. ${ }^{12,13}$ This fibrotic layer also contributes to an isolated niche which makes the interface more susceptible to device-associated bacterial infections. ${ }^{14,15}$

Given its role as a nucleus of the foreign body reaction, reducing protein adsorption to the implanted device is essential and efforts have focused in large part on affording an interface with antifouling characteristics. Interfaces which present certain chemical functionalities (Figure 2) are often the most effective at reducing protein adsorption and yielding antifouling character, with these typically following the so-called "Whitesides rules.." ${ }^{\prime \prime}$ s surface which 
Biosketches
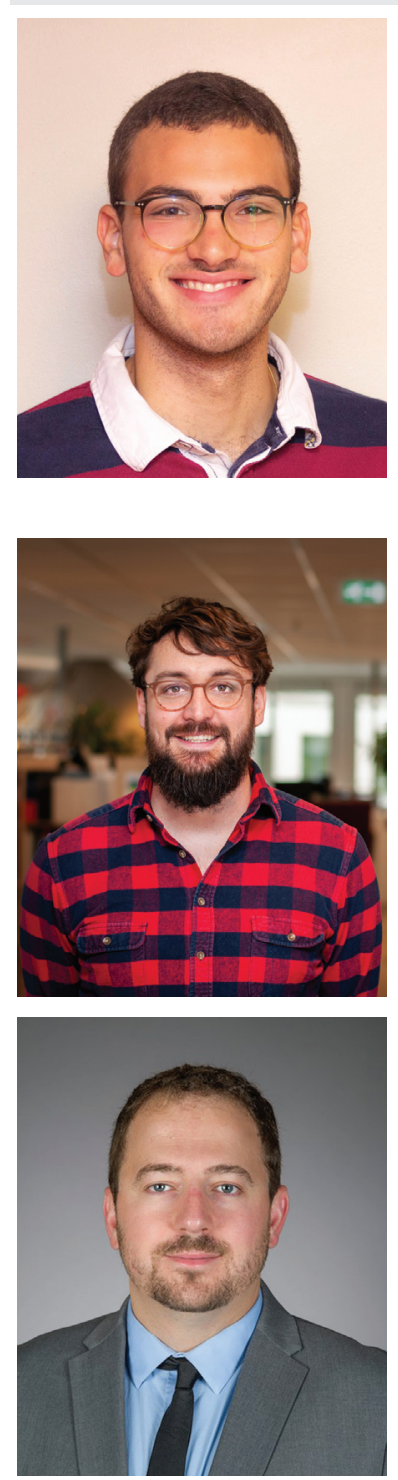

Matthew J. Webber is an assistant professor at the University of Notre Dame, with an appointment in Chemical and Biomolecular Engineering and a concurrent appointment in Chemistry and Biochemistry. $\mathrm{He}$ received his $\mathrm{PhD}$ in Biomedical

is generally hydrophilic is a common feature for antifouling function. In fact, a strongly adhered layer of surface-bound water molecules affords both a physical and a thermodynamic barrier to protein adsorption, ${ }^{16}$ as water molecules need first to be displaced from favorable interactions in order for fouling to proceed. ${ }^{17}$ For the creation of such a water layer, both physicochemical properties and surface packing are believed to play a role. Additionally, it is strongly advantageous for the overall surface charge to be neutral; all proteins contain negatively and positively charged residues, which will consequently drive electrostatic association with a charged surface. ${ }^{18}$ In the case of polymer-modified interfaces which repel protein adsorption, chain flexibility is also important both to introduce steric effects and also to
Institute under the supervision of Prof. Matthew B. Baker and conducted his Bachelor Thesis Research in The University of Notre Dame under the supervision of Prof. Matthew J. Webber. He is presently pursuing an MPhil in Chemistry with the lab of Prof. Oren A. Scherman in the Melville Laboratory for Polymer Chemistry at the University of Cambridge.
Engineering from Northwestern University under the direction of Prof. Samuel Stupp and was an $\mathrm{NIH}$ postdoctoral fellow at MIT under the direction of Profs. Robert Langer and Daniel Anderson. His lab at Notre Dame is focused on rationally de- thesis and characterization of dynamic hydrogels, supramolecular polymers, advanced biofabrication materials, and biomimetic mechanophores for applications in tissue engineering. tute at Maastricht Unive assistant professor in 2017. His research interests include the syn- signing materials, beginning with principles from supramolecular chemistry and peptide self-assembly, with an emphasis on new strategies for drug delivery.

couple protein adhesion with an unfavorable decrease in surface entropy. ${ }^{19}$ Finally, a common feature of antifouling surfaces is a large number of hydrogen bond acceptors combined with the lack of hydrogen bond donating groups. $^{20,21}$ Combating protein adsorption has thus been explored primarily by engineering the interface to present these chemical functionalities.

One of the most commonly explored routes to introduce antifouling chemical functionality on the surface of a biomaterial is through decoration with hydrophilic polyethylene glycol (PEG). ${ }^{22}$ The procedure of introducing a PEG coating has been shown to dramatically decrease protein adsorption to a surface. ${ }^{23}$ While PEG has been among the most explored of these approaches, recent literature has 


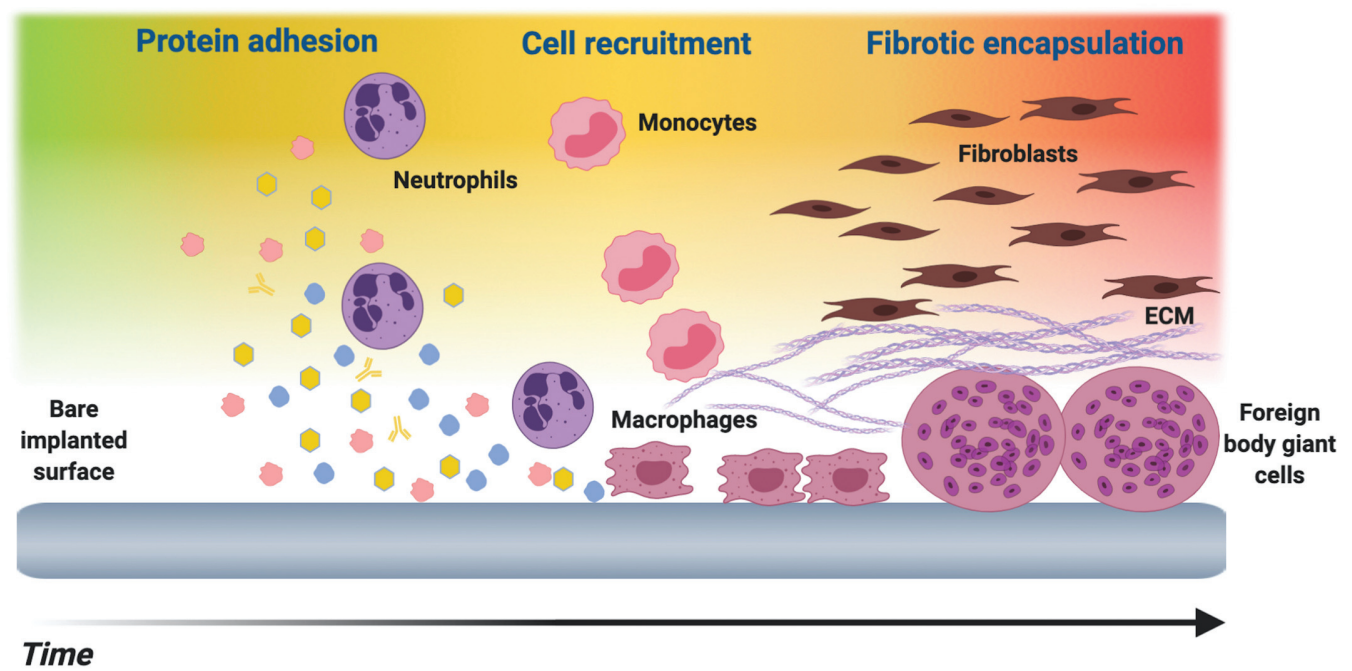

Figure 1 Simplified host responses to a noncompatible material.

suggested the formation of PEG-specific antibodies which indicate the possibility of an immune reaction specific to this method of coating. ${ }^{24}$ Furthermore, PEG has been reported to oxidize in vivo upon exposure to superoxide species produced by leukocytes and macrophages, yielding a number of reactive aldehyde products which may prove problematic to the safety and compatibility of a material. ${ }^{25-27}$ Accordingly, due to recent concerns with PEG, efforts have refocused on other materials which could also impart hydrophilicity at a material-tissue interface.

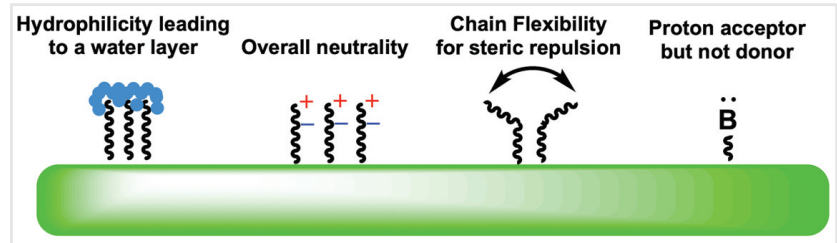

Figure 2 Structural and chemical criteria for displaying antifouling properties.

The pursuit of alternative surface chemistries to PEG has taken biological inspiration from, among other things, zwitterionic phosphorylcholine (PC) groups which form the hydrophilic "head" of common phospholipids in cell membranes and have been shown to have antithrombogenic properties. $^{28,29}$. These zwitterions strongly interact with water through hydrogen bonding, promoting an antifouling character. ${ }^{30}$ With this observation, other modified zwitterionic structures were synthesized by rearranging the inner salt composition and modifying the charged moieties, including carboxybetaine (CB), sulfobetaine (SB), and phosphobetaine (PB; Figure 3) ${ }^{31}$ In each of these, a quaternary ammonium species is tethered to a carboxylic, sulfonate, or phosphate group respectively, via an alkyl spacer. The betaine class of zwitterions is theoretically any amphoteric species; however, conventionally the cationic structure is implied to be an ammonium group while the anionic constituent serves to name the compound. ${ }^{32}$ While the structure of PC could technically fall within the PB subgroup, the orientation of the ionic groups is switched for this motif and PC is considered its own class. ${ }^{33}$ In accordance with traditional naming standards, the betaines referred to in this article are exclusively those with a terminal anionic group.

$$
\text { Sulfobetaine (SB) }
$$

Carboxybetaine (CB)<smiles>[R][N+]([R])([R])CCOP(=O)([O-])O</smiles>
Phosphobetaine (PB)<smiles>[R]OP(=O)([O-])OCC[N+](C)(C)C</smiles>

Phosphorylcholine (PC)
Figure 3 Chemical structures of the most common betaines and phosphorylcholine.

The similarities between each class of betaines has led to their evaluation in various biomedical applications toward improving surface properties and addressing protein adsorption and the ensuing foreign body reaction. ${ }^{34}$ Given the broad scope of literature on these materials, here we endeavor to specifically outline the many uses of $S B$, although in many cases a related zwitterionic motif may be used interchangeably. While SB has been implemented for a number of nonmedical applications, such as marine coatings, batteries, and oil-water separations, this review will 
focus specifically on its biomedical uses. ${ }^{35-37}$ Furthermore, though SB has shown an ability to prevent bacterial fouling, this will not be discussed in the context of this review and the reader is instead encouraged to further examine existing reviews on this topic. ${ }^{38-42}$ Herein, we will specifically focus on the history of SB use in biomaterials design, the underlying chemistry giving rise to SB motifs, the methods for grafting of SB coatings, and finally a discussion on the application of SB materials spanning membranes, nanoparticles (NPs), selectively binding surfaces, and gene delivery vectors. Finally, some insight will be provided with regards to the benefits and drawbacks of SB coatings relative to functionally similar approaches based on other zwitterions.

\section{History of Sulfobetaine Use in Biomaterials}

The history of SBs in particular is intertwined with advances in the understanding and practice of biomaterials. The connection of surface wettability with biocompatibility and antifouling properties was one of the first surface chemistry relationships explored for biomaterials. ${ }^{43,44}$ Betaines, which were previously applied as wetting agents in cleaning products and as osmoregulators, were therefore a promising moiety to create antifouling surfaces, inspiring some of the early studies of SB for coating biomaterials. ${ }^{45-48}$ Much of this initial work focused on fibroblast adhesion and bacterial attachment. Later, SBs were explored for their hemocompatibility, with the antithrombogenic properties of sulfate groups inspiring studies on the reduction of platelet adhesion and blood coagulation. ${ }^{49,50}$ One of the first targets was an effort to improve the hemocompatibility of common segmented poly(urethane) biomaterials. ${ }^{51}$ These studies found that SB modification greatly improved the surface hydrophilicity, which eliminated the adsorption of proteins and adhesion of platelets. ${ }^{52}$ Further studies combining simulations and experimental work found that balanced charges and a minimized dipole are two main molecular contributors to the antifouling performance of SB and related zwitterions, which expanded the understanding of the utility of the SB motif beyond functions linked exclusively to the sulfonate group. ${ }^{53}$ Subsequent work found that fibrinogen adsorption and cell adhesion were completely inhibited in an SB-modified glass substrate. ${ }^{54}$ These early efforts solidified the importance of SB as a useful candidate moiety for altering the outcome of many common complications arising on biomaterial surfaces.

\section{Sulfobetaine Chemistry}

The introduction of SB as a coating on a biomaterial can be achieved by a number of methods. Most commonly,
SB-containing polymers are employed wherein the chain length and multifunctionality improve steric inhibition at the surface with a better surface distribution of these antifouling chemical moieties. Additionally, some efforts to introduce SB via in situ modification of the biomaterial surface have proven successful. A number of structures entailing modified SB motifs have been employed and explored, as shown in Figure 4.

The modification of methacrylic acid to achieve a presented SB functionality has enabled a variety of monomers for SB incorporation into routinely synthesized polymeric materials (Figure 4a). Different synthetic strategies result in SB groups attached via an ester (SBMA) or amide (MAASB), with no difference observed for the overall antifouling properties of the resulting materials. ${ }^{55}$ In another approach, vinyl benzyl monomers have been modified to present the SB functionality (VBSB); despite less prevalent use, pVBSB affords the synthetic versatility to form polymer brushes and endow interfaces with antifouling properties. ${ }^{56,57}$ Routes have also been explored to vary the alkyl lengths between the ammonium and sulfate groups in the creation of functional monomers suitable for polymerization. ${ }^{58}$ Recently, the traditional SB structure was combined with a triazole group (TRSB), introducing a new zwitterionic monomer to the literature. ${ }^{59}$ Despite the increased complexity of the synthesis, the mechanical properties of the resulting gels were improved while excellent antifouling properties were maintained.

In addition to variations in polymer backbone and pendant SB topology, systematic structure-property relationships have also been explored for the SB moiety. One variation to the structure of the zwitterion was lengthening the alkyl substituents on the ammonium from methyl to ethyl groups (Figure $4 \mathrm{~b}) .{ }^{60} \mathrm{SB}$ moieties prepared from methyl groups were observed to better prevent platelet adhesion when compared to the ethyl analogue. The observed reduction in performance was attributed to the increased shielding of the cationic group via the ethyl substituents, impacting its hydrophilic character. The anionic component has also been studied, with the regiochemical attachment of SB investigated through branched forms (Figure 4c). ${ }^{61}$ In this work, linear SB analogues generally provided better antifouling properties than did the branched variants, but these worked quite well also. A more comprehensive set of structures has also been examined by altering the alkyl chain lengths and ammonium functional moieties (Figure 4d). ${ }^{62}$ The results from studies to vary the chemical topology and features of SB motifs point to subtle and complex structureproperty relationships for antifouling performance. ${ }^{63}$ The continued exploration of new structural variants is important to further understand and optimize the performance of SB materials for antifouling applications. ${ }^{64}$

Rather than conducting polymerization beginning from SB-bearing monomers, this chemical functionality can 


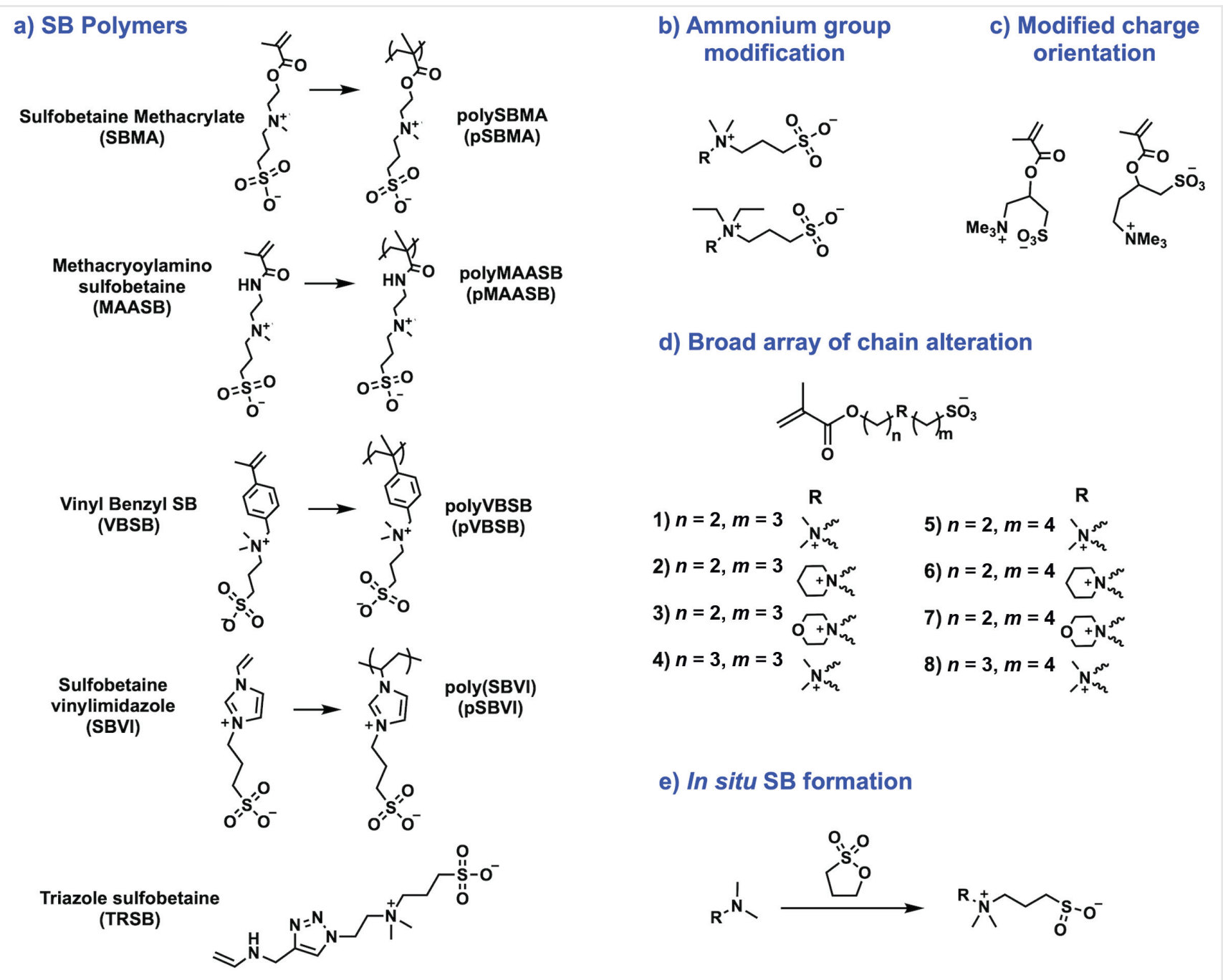

Figure 4 Chemical structures of sulfobetaines used in antifouling applications: a) SB-containing polymers for coating, b) variations in the substitution of the ammonium group, c) alteration of charge orientation or regiochemistry, d) systematic variants of SB structures, and e) in situ SB generation from tertiary amines.

instead be inserted post-synthetically onto polymer coatings bearing (tertiary) amines via the ring opening of 1,3propanesultone (Figure 4e). ${ }^{65-68}$ This synthetic approach has also been leveraged to form SB directly on the surface of a biomaterial containing tertiary amine groups. ${ }^{31,69-71}$ This approach allows for commercially available monomers, such as 2-(dimethyl-1-amino)ethyl methacrylate to be used in conjunction with standard methods of radical polymerization, with the zwitterionic SB motif included following synthesis instead of necessitating specialty monomers. ${ }^{72}$

\section{Surface Modification}

In order to realize the function of SB-based coatings on biomaterial devices, an assortment of routes have been developed to append or affix SB groups. The methods available to achieve such modification depend on the surface chemistry of the substrate to be modified and the desired SB functionality and may include growing polymers directly from a substrate, covalently appending synthesized polymers, or relying on passive adsorption or coating methodologies to adhere a layer of an SB-containing material at the substrate interface.

\section{Graft-to and Graft-from Polymer Functionalization}

A major challenge when creating zwitterionic coatings is ensuring stable anchorage with the substrate surface. Although there may be applications where a sheddable surface coating is desired, most applications seek a stable 


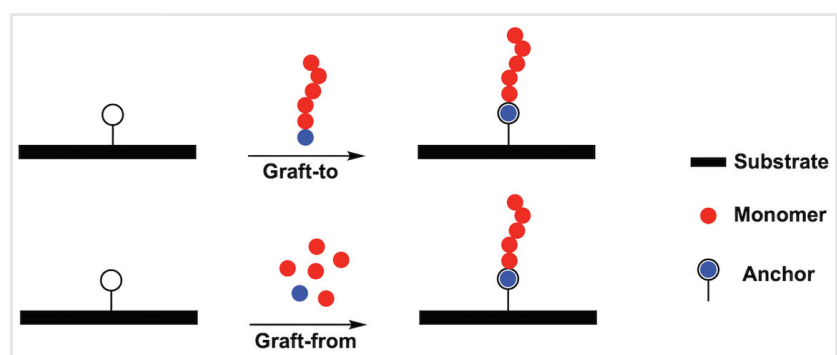

Figure 5 Difference between graft-to (top) and graft-from (bottom) methodologies.

coating which is resistant to desorption under typical physiological conditions. In achieving a brush polymer coating, either graft-to or graft-from methodologies are commonly used (Figure 5). ${ }^{73,74}$ The distinction between these two methods is that in graft-from approaches a polymer is grown at the interface from a surface-presented initiator, while in graft-to methods a presynthesized polymer is covalently attached to the surface. ${ }^{75}$

With graft-from methodology, a polymer initiator is introduced on the substrate to begin polymerization. Commonly, this is achieved with surface-initiated atom transfer radical polymerization (ATRP), as this method of "living" free-radical polymerization offers control over both the molecular weight and dispersity of the polymers formed. ${ }^{76-78}$ An alkyl halide is normally used as the initiator, and frequently 2-bromoisobutyryl bromide is conjugated to a free amine on the surface. ${ }^{79}$ SB coatings have been created on supramolecular materials prepared from ureido-pyrimidinone motifs through inclusion of a similar alkyl halide ATRP initiator. ${ }^{80}$ In earlier work on graftfrom SB coatings, ATRP was instead initiated from peroxide surface groups obtained through ozonation, ${ }^{81}$ which showed promising results in reducing adsorption of platelet-rich plasma. ${ }^{82}$ When a hydroxyl group is present on the substrate, a ceric ion (in the form of $\left.\mathrm{Ce}\left(\mathrm{NO}_{3}\right)_{4}\right)$ can also be used as an initiator to achieve graft-from ATRP polymerization. ${ }^{83}$ For example, this chemistry was successfully employed for creating SB coatings on catheters and films, enabling improved hemocompatibility compared to nongrafted substrates which yielded a large number of adhered platelets. ${ }^{84,85}$

Although the ATRP methodology is the prevailing graftfrom approach for SB materials, Azobisisobutyronitrileinitiated free-radical polymerization has also been employed through the use of a spacer between the SB coating and the substrate; examples of such spacers include hydroxyethyl methacrylate and acrylic acid. ${ }^{86,87}$ Another "living" free-radical method, reversible addition fragmentation chain transfer polymerization, has also been used with SB and similar to ATRP ensures a well-controlled molecular weight. This method requires that a thiocarbo- nylthio chain transfer agent (CTA) be attached to the biomaterial surface. The CTA is then integrated at the terminal position of growing polymers, yet its role in the antifouling properties of the resulting coating remains unclear. $^{88}$

For polymeric zwitterions, most graft-from techniques are used to create SB homopolymers, though other monomers or even crosslinkers have occasionally been explored. ${ }^{55}$ In fact, the presence of crosslinks permits a coating more resistant to desorption, where oxidative instability can be mediated. ${ }^{89}$ Benefits of a graft-from approach include the ability to leverage a very stable anchor to yield a resistant polymer coating as well as the ability to produce surfaces with high grafting densities. A variation of graft-from methodology has explored two-step polymerization, wherein a polymer is first grown and subsequently modified to present SB groups. ${ }^{55,90}$

One consideration that may be especially important for graft-from attachment approaches is ensuring the purity of the coating and removal of catalyst and unreacted monomers. Indeed, the relationships between purity and device performance and biocompatibility have not been extensively explored. Previous work has found that a 4-day procedure to remove unreacted components was insufficient to remove copper complexes, which may remain complexed within the polymer brush. ${ }^{91}$ While the presence of such impurities was not specifically correlated with the impact on biocompatibility of zwitterionic coatings, copper ions are known to possess cytotoxic properties when contaminants remain from its use in copper-catalyzed "click" chemistry ligations. ${ }^{92}$

In graft-to methodology, polymerization is performed separately, allowing for more thorough characterization/ purification of polymers and for the generation of diverse and/or well-defined structures. Graft-to methods necessitate strong and typically covalent anchoring to the surface which is to be modified (Figure 6). To afford presentation of SB groups on the exterior of a coating, other groups are typically included to facilitate anchorage, often by copolymer synthesis. For example, integration of glycidyl methacrylate groups enables epoxide ring-opening to anchor SB polymers to a hydroxylated surface. ${ }^{93}$ Alternatively, inclusion of tyramines within an SB polymer enables enzymatic catechol formation and attachment of these polymers to the surface via a bioinspired adhesion approach. ${ }^{94}$ The attachment of SB polymers via functional polymer chain end groups can also be leveraged. Terminal carboxylates can be used for anchoring SB polymers to an amine-containing surface by routine amide bond formation with 1-ethyl-3-(3-dimethylaminopropyl) carbodiimide (EDC). ${ }^{95}$ Avariation on EDC chemistry has also been used to couple an amine-terminated polymer to a carboxylic functional group on a surface. ${ }^{60,95}$

Catechol chemistry affords an attractive route to anchor SB polymers to the surface of a biomaterial, as catechols 
a) Functional anchoring in polymers

\section{GMA-co-SBMA}

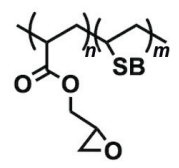

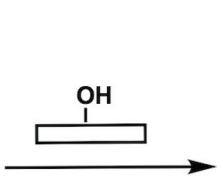

TA-co-SBMA
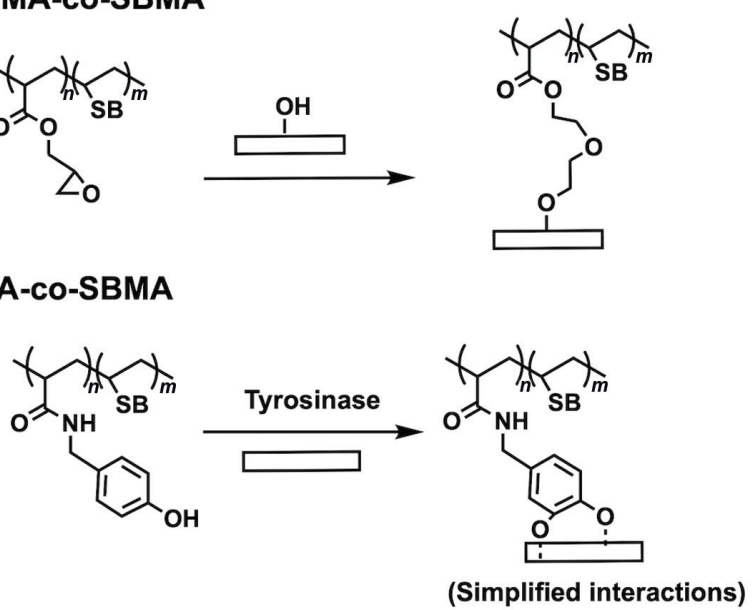

\section{Carboxyl-terminated pSBMA}
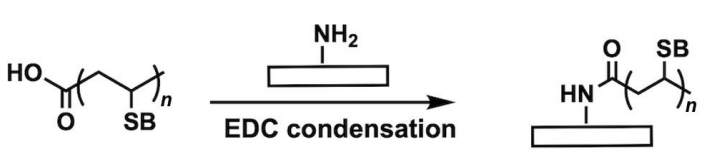

b) Monomer anchoring to substrate

\author{
Click Chemistry
}

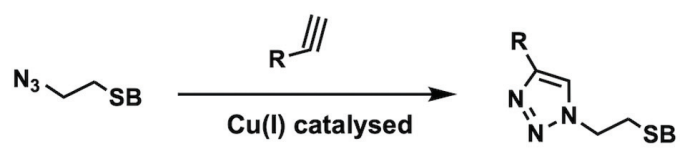

\section{Condensation Reaction}

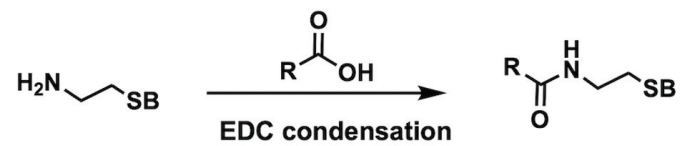

SB Siloxane (SBSi) Coupling

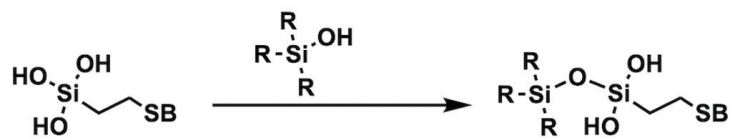

EDC condensation R Hó SB

\section{c) Non covalent interactions}

Layer-by-layer electrolyte deposition

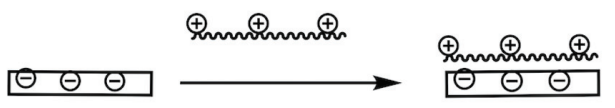

Hydrophobicity-driven coating

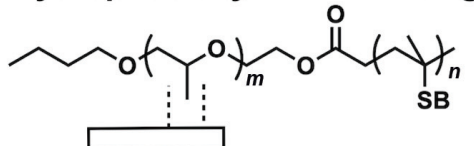

Figure 6 Different anchoring strategies over: a) functional anchoring to polymers, b) single SB moiety binding, and c) noncovalent interactions.

(e.g., dopamine) are able to interact with the surface of a material through both covalent and noncovalent (e.g., hydrogen bonding, charge transfer, and $\pi$-stacking) interactions in appending polymers. ${ }^{96-98}$ Accordingly, catechol chemistry has been applied in graft-to methods using the end group of a synthesized polymer through its initiator, ${ }^{79}$ as well through copolymerization of SB with a catecholbearing monomer. ${ }^{99}$ Dopamine can also be used to modify a surface for the later attachment of SB brushes. ${ }^{100}$

Related routes to the graft-to methodology have been utilized to attach small-molecule SB compounds, as opposed to polymers. An azide-modified SB has been attached via "click" chemistry to alkyne-modified polymers or surfaces. ${ }^{101,102}$ Likewise, siloxane-modified SBs have been used to coat a silica surface. ${ }^{103,104}$ Finally, amide bond formation has been employed to coat surfaces with smallmolecule SB. ${ }^{60}$ In general, these small-molecule-function- alized surfaces have good performance, yet are not able to achieve the high functional density of SB units afforded by polymer coatings.

\section{Noncovalent Coating}

In the absence of covalent modification, SB-containing polymers may still be adsorbed to a surface through noncovalent association. A common approach to coating surfaces is layer-by-layer (LBL) deposition, a method wherein alternating coatings of positively and negatively charged polymers are adsorbed to a growing surface via electrostatic interactions. ${ }^{105}$ Although SB groups are netneutral, routes have been implemented to include these in LBL coatings through the creation of copolymers with groups bearing negative charges. ${ }^{106}$ Another common 
surface coating method, chemical vapor deposition, ${ }^{107}$ has been integrated with SB coatings through the postmodification of deposited poly- $p$-xylylene onto a substrate. ${ }^{102}$ Yet another common deposition method, electrospinning, has been used to adsorb SB-containing copolymers, and was demonstrated in an approach to increase the biocompatibility of poly-L-lactic acid films. ${ }^{108}$ Electrospun surfaces can also be modified using the same catechol chemistry discussed above to attach polymers with SB groups. ${ }^{109}$ Finally, hydrophobic-driven association of amphiphilic block copolymers has also been explored for the adsorption of SB-containing polymers onto hydrophobic surfaces. ${ }^{110,111}$ Although noncovalent associations of SB polymer coatings have generally demonstrated promise, implications of their erosion over time following implantation should be considered.

\section{Applications of Sulfobetaine Coatings}

\section{Membranes}

Membranes are common in filtration applications or as semipermeable barriers in biomedical use as well as in biology-adjacent fields. The adhesion of proteins to a membrane compromises its function and lifetime, and antifouling coatings based on SB and related chemistries may provide a versatile solution to address many problems. ${ }^{112}$ For example, polypropylene nonwoven fabric membranes are used for both plasma separation and municipal wastewater treatment; SB coatings on such materials therefore offer enhanced performance in multiple applications. ${ }^{113-117}$ The use of SB coatings to improve membrane properties has been applied to a variety of substrates, including polyvinylidene difluoride, aromatic polyamides, poly(aryl sulfones), polypropylene, and regenerated cellulose. ${ }^{118-122}$ The coating methodology for these membranes includes techniques in graft-from, graft-to, hydrophobic-driven coating, and related self-assembled depositions. ${ }^{55,110,123,124}$ In other instances, SB groups were introduced onto membranes by in situ polymerization of SBMA. ${ }^{125}$

Protein fouling on membranes designed for hemodialysis is a significant issue with severe consequences. For blood-contacting applications, membrane properties are typically evaluated using bovine serum albumin as a model fluid. ${ }^{126,127}$ Historically, cellulose-based membranes have been used for this application, ${ }^{128}$ and early reports explored grafting SB to regenerated cellulose to improve blood compatibility. ${ }^{129,130}$ Today synthetic polymer materials are primarily used, ${ }^{131}$ yet the benefits of SB-coated cellulose have been extended to water treatment applications. ${ }^{132}$

Wound care is another application explored for SBcoated membranes. A biocompatible membrane of expand-

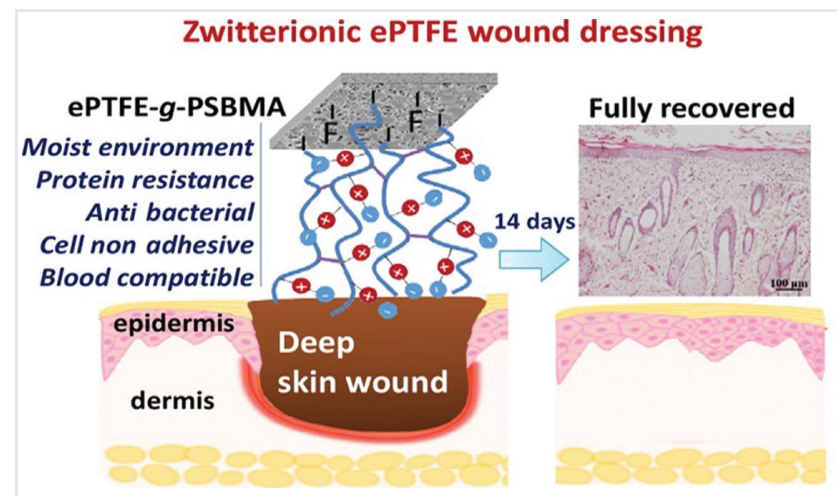

Figure 7 Enhanced wound healing from an SB-coated membrane. Adapted with permission from Ref. 133. Copyright 2013 American Chemical Society.

ed polytetrafluoroethylene was functionalized with pSBMA to afford humidity control from the hydrophilic character of the zwitterion (Figure 7). ${ }^{133}$ In this use, superior water absorption was observed which contributed to more rapid re-epithelialization compared to a non-SB functionalized dressing. This approach was also extended to SB-coated chitosan membranes for diabetic wound healing. ${ }^{134}$ This coating accelerated wound healing time, with regeneration approaching normal physiologic skin, including restoration of hair follicles. Beyond membrane-based dressings, SBcontaining hydrogels based on pSBMA have been explored, showing enhanced wound healing in full cutaneous defects in mice. ${ }^{135}$ In particular, softer hydrogel formulations had greater regeneration. ${ }^{136}$ The improvement on wound healing upon SB incorporation has also been seen when included within PEG hydrogel dressings. ${ }^{137}$

\section{Nanoparticles}

NPs have been explored for a variety of biomedical applications ranging from diagnostic imaging to drug delivery to vaccination. When NPs are present in physiological environments, protein adsorption to form a corona is responsible for a significant size increase, agglomeration, masking of the NP surface, and loss of function. ${ }^{138}$ Furthermore, the protein corona can enhance phagocytosis of NPs; although this may be desired in certain applications, in the wrong settings such uptake leads to reduced circulation time, inefficient target delivery, and unsatisfactory pharmacokinetics. ${ }^{139,140}$ "Stealth" NPs have been a target of interest, which include antifouling coatings to prevent unwanted protein adsorption. ${ }^{141-143}$ SB thus offers an appealing approach to limit protein adsorption and fouling of NPs broadly. The first report of SB coating of NPs was based on gold (Au-NP), where facile thiol modification 
allowed for improved NP colloidal stability upon grafting SB monomers. ${ }^{144}$ This method is indeed a versatile approach to alter the surface chemistry of a variety of NPs. ${ }^{145}$ Polymeric coatings have also been demonstrated, with SB polymers first prepared through graft-from ATRP using SBMA polymerization from a magnetic bead substrate. ${ }^{146}$

Superparamagnetic iron oxide NPs (SPIONP) have been explored for a number of biomedical applications, ${ }^{147}$ including as magnetic resonance imaging contrast agents ${ }^{148}$ and tissue-engineering scaffolds. ${ }^{149}$ The dispersal of SPIONPs remains a challenge in aqueous media, as ligand exchange occurs post-synthesis. The direct coupling of SB monomers was shown to both stabilize SPIONP during synthesis and provide a hydrophilic zwitterionic coating. ${ }^{150}$ Dopamine-mediated anchoring of SB monomers has also been employed for successful dispersal of SPIONP in solution; these SB-coated SPIONPs showed utility in tumor imaging. ${ }^{151,152}$ A recent report shows the possibility of coating graft-from SB brushes and SB membranes on iron oxide NPs, with SB membranes improving antifouling resistance compared to the polymeric brushes. ${ }^{153}$ However, this coating technique significantly increases the hydrodynamic radius, which may introduce complications in prolonging exposure leading to toxicity. ${ }^{154}$

While NPs have primarily been coated with SB to increase circulation time, functionalized NPs have also been utilized as a biomaterial surface coating by depositing SBmodified silica NPs onto a material. ${ }^{104}$ These NP films exhibited low protein adsorption, and reduced attachment of fungi and spores. In a subsequent study, the importance of topography on the antifouling performance of these NP films was shown. ${ }^{155}$ Most recently, an additive effect of dual functionalization with SB and quaternary ammonium silane was demonstrated. ${ }^{156}$

Quantum dots (QDs) are also useful, as their unique optical and electronic properties allow for imaging-based diagnostics with high and stable signals. ${ }^{157}$ Like with other NPs, QDs are subject to overly fast clearance from the body and thus coating with SB has been explored as a strategy to provide longer circulation half-life. For instance, dihydrolipoic acid (DHLA) has been used as an anchoring unit for modification with an SB-group to impart a zwitterionic coating to QDs to increase circulation times, enhance biodistribution, and reduce liver uptake. ${ }^{158}$ DHLA-SB coated QDs were also found to have reduced aggregation and enhanced stability of QD within the cytosol compared to PEG-based coatings and commercial QD formulations. ${ }^{159}$ In particular, DHLA-SB was found to be superior to PEG coatings due to the reduced size, improved protein antifouling function, preserved optical properties, and maintained stability in various $\mathrm{pH}$ and salinity levels over long times. ${ }^{160}$ In addition, SB coatings can also be employed during the QD synthesis in order to facilitate ease of use and biocompatibility without ligand ex- change. ${ }^{161}$ One of the challenges for QD functionalization with SB is ligand desorption, and a correlation between rate of ligand desorption and QD performance has been characterized. Coatings with thiol-based anchoring groups proved to be more effective when in a multidentate ligand conformation, as two lipoic functional groups on a single SB moiety was shown to provide better stability than a single group. ${ }^{162,163}$ Importantly, maintaining a compact coating with a small hydrodynamic radius has been a priority to avoid dramatic size increase from the surface coating. ${ }^{164}$

The demonstrated longevity and antifouling properties of SB-coated QDs have led to the exploration of specific binding groups incorporated on the QDs. ${ }^{165}$ For example, SB-containing block copolymers were prepared with vinyl imidazole, used for anchoring, and $\mathrm{N}$-(3-aminopropyl) methacrylamide to afford an amine handle for protein conjugation. ${ }^{166}$ The resulting QD was stabilized, and upon unmodified antibody addition the level of specific antigen binding is high. Furthermore, these coatings were sensitive to $\mathrm{pH}$ change, and have been used as standards for developing pH-responsive QD nanoprobes. ${ }^{167}$ In other efforts to append functional groups to these coating, "click" chemistry ligation of RGD ligands has been achieved with azide-containing SB copolymers, though the modification did not result in higher tumor uptake of the particles. ${ }^{168}$ More recent work has shown that folic acid functionalization of similar QDs does enable targeting and selective uptake in cancer cells. ${ }^{169}$

\section{Selectively Binding Surfaces}

While in many cases a reduction in nonspecific protein adsorption is desired, applications in recognition and sensing often require binding specificity for certain proteins or analytes. In fact, a particular class of materials can be recognized: those surfaces that exhibit selectively and strongly interacting properties with one desired substrate while repelling all other molecules in a medium. ${ }^{170}$ SB has been used in several examples where both antifouling and selective recognition were required. Copolymerization of SBMA with $\mathrm{N}$-methacryloyloxysuccinimide via ATRP provided a brush-like surface to which concanavalin A (a sugarbinding protein) could be covalently attached. These surfaces showed the ability to selectively sense mannose in the presence of background proteins. ${ }^{171}$ Alternatively, pMAASB brushes were prepared on indium tin oxide via ATRP and the terminal bromine was substituted with an azide group. This azide was shown to facilitate the attachment of biotin to the periphery of the layer and enable the specific recognition of streptavidin in the presence of background proteins (Figure 8). ${ }^{172}$ This general method enables possibilities to introduce a number of 


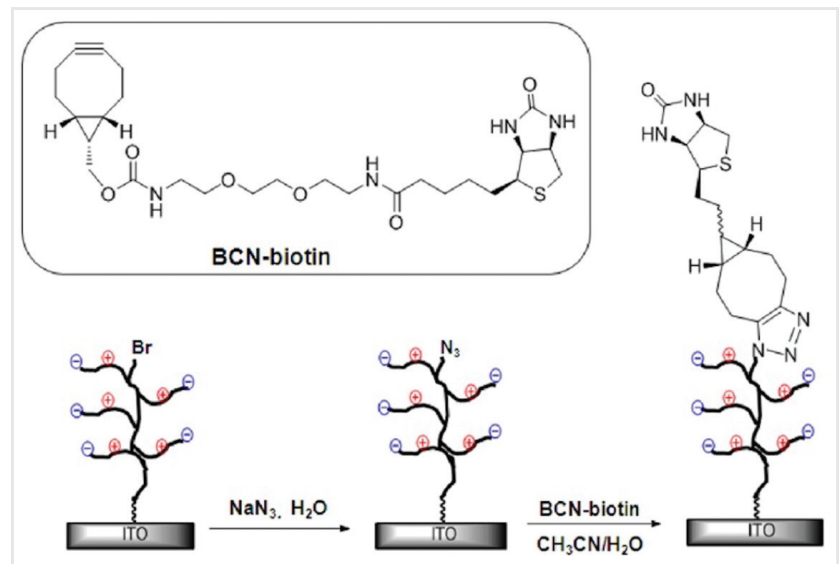

Figure 8 Functionalization of pMAASB brushes with a terminal biotin ligand. Reprinted with permission from Ref. 172. Copyright 2012 American Chemical Society.

specific ligands in the coating using "click" chemistry, and even the presentation of a variety of antibodies through EDC coupling chemistry. ${ }^{173,174}$

\section{Applications of Sulfobetaines: Beyond Coatings}

\section{Polymeric Micelles and Assemblies}

Micelles are commonly formed from the self-assembly in water of amphiphilic molecules. As mentioned, many lipids have zwitterionic headgroups; zwitterionic molecules and polymers based on SB can similarly be used to form micelles and may enable applications such as encapsulating hydrophobic drugs. ${ }^{175}$ The SB polymer architecture has also been investigated for its impact on micelle formation, with star copolymers showing improved micelle formation and tunable rates of drug release. ${ }^{176}$ The size of these SB polymer micelles was also shown to impact cellular uptake. ${ }^{177}$ Micelles prepared from star-shaped copolymers also exhibited reduced cytotoxicity compared to linear variants, ${ }^{178}$ while factors such as polymer concentration and composition also influence micelle formation and drug release. ${ }^{179}$ Further efforts have explored copolymerization of SB with groups to enable $\mathrm{pH}$-responsive properties (Figure 9), for $\mathrm{pH}$-triggered release of encapsulated drugs. ${ }^{180}$ Redox-sensitive disulfide bonds have also been introduced, ${ }^{181}$ enabling a $\mathrm{pH}$ and redox dual-responsive micelle.

The encapsulation and efficient delivery of genetic material in biomedical applications remains a continued challenge with broad possible impact. Typically, nucleic acids are formulated to form condensed particles with a polyelectrolyte vector to facilitate delivery, although charge neutralization can lead to precipitation of DNA and reduce its stability. Due to their overall neutrality while maintaining charge-bearing groups for condensing nucleic acids, SBbased materials offer an interesting alternative. In an early example, SB units on a prepared tri-block copolymer were found to effectively complex with DNA. ${ }^{182}$ A variety of SBcontaining copolymers have since been developed, and the importance of selecting a hydrophobic monomer to copolymerize with the SB-containing group has been noted for efficient complexation and delivery of nucleic acids. ${ }^{183-185}$ In one in vivo study, SB was used successfully to elicit the expression of red fluorescence protein, ${ }^{186}$ with SB incorporation promoting a dramatic increase in transfection efficiency compared to polyethylenimine.

\section{SB-Based Hydrogels}

The enhanced biocompatibility realized for SB-coated materials has led to the exploration of hydrogels based on SB-containing polymers. Hydrogels are able to retain large

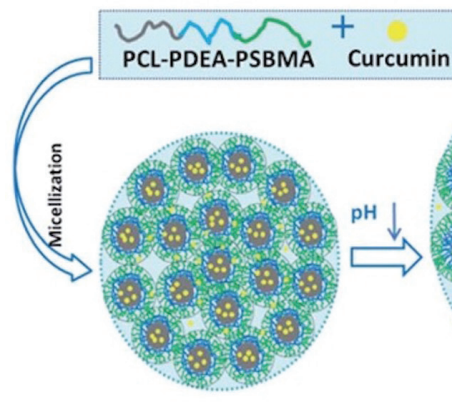

$\mathrm{pH} 7.4-7.0$

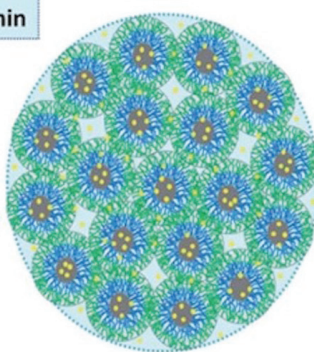

pH 6.5-5.5

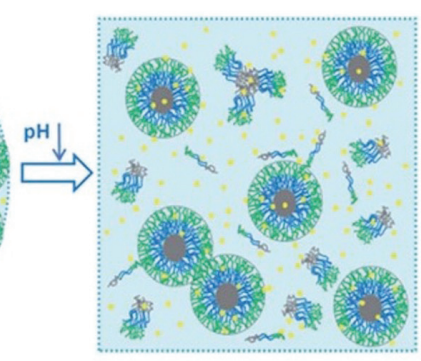

pH 5.0-4.5

Figure 9 Preparation and application of pH sensitive micelles from an SB-containing terpolymer encapsulating a hydrophobic drug. Reprinted with permission from Ref. 180. Copyright 2014 Royal Society of Chemistry. 
amounts of water, and their percolated network mesh structure resembles the architecture of native tissue matrices. ${ }^{187}$ To form a hydrogel, some form of physical or chemical crosslinking is necessary. ${ }^{188}$ The formation of hydrogels from SB-based polymers can arise through both physical electrostatic interactions and chemical covalent crosslinking, with simultaneous formation of these interactions leading to a double network characterized by highly tunable mechanical properties. ${ }^{189}$ The nature of these electrostatic interactions makes them highly sensitive to the concentration of ions (e.g., the Debye length), and as such salt-responsive swelling has been realized through salt addition. ${ }^{190}$ SB-based polymers have also been used to form hydrogels through addition of crosslinkers in the synthesis to enable tunable mechanical properties. ${ }^{189}$ Dimethacrylate SB has also been used as a crosslinker during polymerization, ${ }^{191}$ and controlled synthesis can lead to better mechanical properties. ${ }^{192}$ An initial in vivo study of SB-based hydrogels found low cell-based interactions and enhanced vascularization. ${ }^{193}$ Newer iterations of these hydrogels have explored the addition of groups for sensitivity to $\mathrm{pH}$ and temperature. ${ }^{194-196}$ Glucose-sensing proteins have been included within SB hydrogels as well. ${ }^{197}$ Hybrid hydrogel materials have also been reported, such as the creation of nanocomposite SB hydrogels through addition of clay platelets to achieve high tensile strength. ${ }^{198-200}$

A recent study evaluated SB-based modification of alginate hydrogels for pancreatic islet encapsulation in efforts to improve the transplantation of these exogenous cells to reverse type- 1 diabetes. ${ }^{201}$ The SB modification of these commonly used hydrogel materials led to a significant reduction in cellular overgrowth and prolonged blood glucose correction in a diabetic mouse model compared to the standard method of encapsulating islets in unmodified alginate. More broadly, this points to the ability to modify a common hydrogel biomaterial to enhance its biocompatibility and overcome fibrosis at the materialtissue interface. As another example, a conformal agar hydrogel coating was also modified with SB moieties to reduce biofouling on catheters. ${ }^{202}$

\section{Comparison to Carboxybetaine}

While it has been established that SB-based coating drastically reduces fouling events, other betaines such as CB display an analogous behavior. Therefore, with respect to selection of SB as the zwitterion of choice, there are several considerations that may be important. ${ }^{203}$ Studies conducting a parallel comparison of SB and $C B$ have been able to quantitatively identify notably improved function for $\mathrm{CB}$ based approaches in reducing fouling in plasma-contacting applications. ${ }^{204}$ This has been justified by a shorter distance between the charged groups in $\mathrm{CB}$ (an ethyl segment in CB vs. a propyl segment in SB), which more effectively stabilizes the dipole moment in water molecules and leads to overall better hydration. ${ }^{203}$ These results contrast with greater contact angles observed for SB analogues which are suggestive of higher hydrophilicity. ${ }^{204}$

It is noteworthy that CB-based materials can be more readily modified through amide bond formation with their terminal carboxylate, although this technique results in a loss of overall neutrality and compromises antifouling ability. ${ }^{205,206}$ Meanwhile features unique to the SB sulfonate group affords certain functional advantages such as the ability to bind DNA and to mimic the structure of sulfated glycosaminoglycans. ${ }^{207}$ One clear advantage of SB is the preservation of its overall neutral charge over a wide range of $\mathrm{pH}$, while $\mathrm{CB}$ can undergo protonation on the carboxyl group at a relatively high pKa. ${ }^{208}$ Accessing $\mathrm{pH}$-sensitive charge states does, however, afford an opportunity for $\mathrm{pH}-$ responsive materials from both zwitterions. ${ }^{209}$ Thus, there are advantages to be realized from choosing either SB or CB (Figure 10), which may be dictated by the synthetic constraints or objectives of a particular application.

\section{Conclusions and Outlook}

On the basis of the many examples shown here, the synthetic strategies for accessing SB-containing materials offer a well-established approach to reduce protein fouling

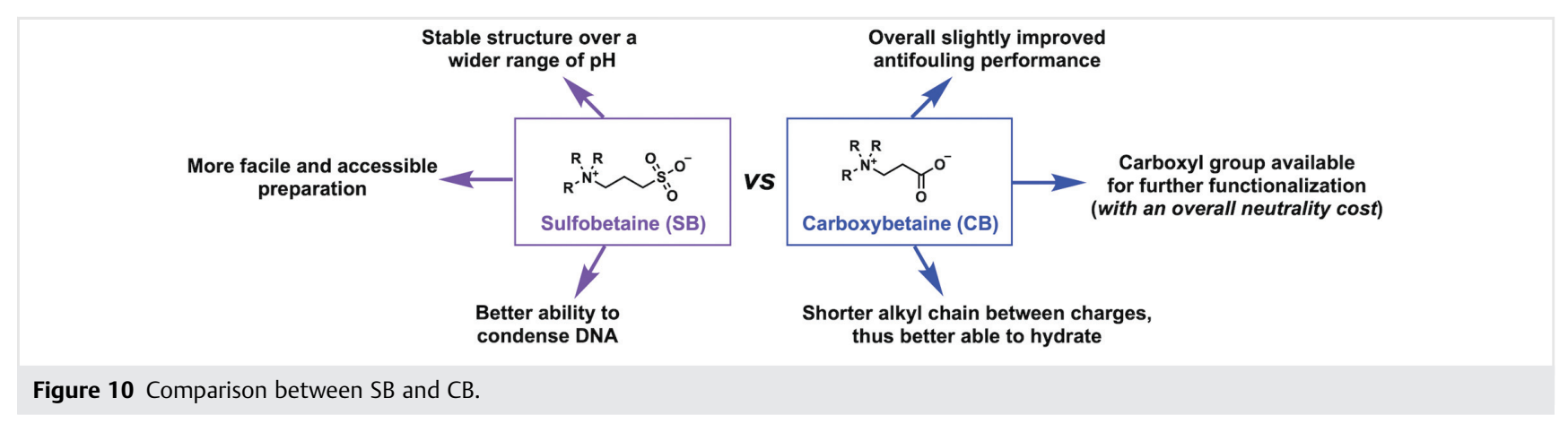


and nonspecific adhesion, with applications spanning biomedical, bio-adjacent, and industrial uses. Studies have shown that SB-based approaches achieve better performance than more commonly used techniques based on PEG. ${ }^{210}$ With the recent demonstration of the occurrence of PEG-specific antibodies in certain uses, ${ }^{24}$ reevaluating the use of synthetic zwitterionic polymers may indeed be warranted across many unexplored applications.

While alterations to the traditional SB structure have been explored, those have had limited success. ${ }^{211} \mathrm{New}$ structures have so far required more complex synthetic pathways, which complicates the preparation of SB-based coatings. ${ }^{61}$ Moreover, progressing to more complicated structures may be unnecessary in light of the accessibility and facile preparation of SB itself, which offers a convenient approach for industrial-scale use. Furthermore, it is also unclear to what extent any modifications improve upon the antifouling properties of the SB moiety. ${ }^{9}$ Certainly, the mode of application and stability of an applied coating are features more likely to dictate the ultimate performance of these materials. $^{212}$

Despite a wealth of literature evaluating SB-based materials for biomedical applications, no materials based on SB have presently secured clinical approval. ${ }^{211}$ This present reality does not in any way detract from the many research advancements, which have significantly advanced knowledge across disciplines ranging from physical chemistry and surface science to biomedical device fabrication. Indeed, the recent increase in exploration of SB-based materials for in vivo evaluations brings their clinical use closer to reality. ${ }^{213,214}$ Beyond surface uses, there are a variety of promising directions for SB-based zwitterion biomaterials in applications such as wound healing or insulin administration, which may be ripe for translation in future years. $^{136,215}$

Many of the possible applications for which the antifouling properties of SB would prove beneficial remain to be explored. For example, there is limited use of SB-based materials to improve the sensitivity and lifetime of biosensors. Although some have viewed the synthetic challenges to implementing these coatings for biosensing as a barrier to their use, ${ }^{216}$ many of the SB-based approaches described here should be relatively facile for their exploration and it is the hope that these approaches will be more thoroughly evaluated toward improved biosensing in the coming years. Beyond this, a future moving ever closer to achieving a human-machine interface using wearable or implantable electronic devices will need scalable and robust methods to ensure long-lived and reliable performance of these devices and to overcome the natural foreign body reaction. ${ }^{217}$ It is envisioned that these and a host of other emerging applications will highlight continued growth and exploration of SB chemistry in the context of biomedical device practice, as new components of sensors, and in a variety of other applications for which fouling compromises reliable performance.

\section{Funding Information}

M.J.W. acknowledges funding support through the University of Notre Dame "Advancing our Vision" initiative. M.B.B. acknowledges financial support from the Province of Limburg.

\section{Acknowledgment}

F.Z. and M.B.B. would like to thank the Maastricht Science Program for guidance and support.

\section{References}

(1) Peppas, N. A.; Langer, R. Science 1994, 263, 1715.

(2) Langer, R.; Tirrell, D. A. Nature 2004, 428, 487.

(3) Webber, M. J.; Appel, E. A.; Meijer, E. W.; Langer, R. Nat. Mater. 2016, 15, 13.

(4) Huebsch, N.; Mooney, D. J. Nature 2009, 462, 426.

(5) Wagner, W. R.; Sakiyama-Elbert, S. E.; Zhang, G.; Yaszemski, M. J. Biomaterials Science: An Introduction to Materials in Medicine. Academic Press: San Diego, 2020.

(6) Anderson, J. M.; Rodriguez, A.; Chang, D. T. Semin. Immunol. 2008, 20, 86.

(7) Grainger, D. W. Nat. Biotechnol. 2013, 31, 507.

(8) Zhou, G.; Groth, T. Macromol. Biosci. 2018, 18, 1800112.

(9) Wei, Q.; Becherer, T.; Angioletti-Uberti, S.; Dzubiella, J.; Wischke, C.; Neffe, A. T.; Lendlein, A.; Ballauff, M.; Haag, R. Angew. Chem. Int. Ed. 2014, 53, 8004.

(10) Gorbet, M. B.; Sefton, M. V. Biomaterials 2004, 25, 5681.

(11) Anderson, J. M. Annu. Rev. Mater. Res. 2001, 31, 81.

(12) Wu, P.; Grainger, D. W. Biomaterials 2006, 27, 2450.

(13) Yu, B.; Wang, C.; Ju, Y. M.; West, L.; Harmon, J.; Moussy, Y.; Moussy, F. Biosens. Bioelectron. 2008, 23, 1278.

(14) Fey, P. D. Curr. Opin. Microbiol. 2010, 13, 610.

(15) Donlan, R. M. Emerging Infect. Dis. 2001, 7, 277.

(16) Zheng, J.; Li, L.; Tsao, H.-K.; Sheng, Y.-J.; Chen, S.; Jiang, S. Biophys. J. 2005, 89, 158.

(17) Chen, S.; Yu, F.; Yu, Q.; He, Y.; Jiang, S. Langmuir 2006, 22, 8186.

(18) Chen, Y.; Thayumanavan, S. Langmuir 2009, 25, 13795.

(19) Jeon, S. I.; Lee, J. H.; Andrade, J. D.; De Gennes, P. J. Colloid Interface Sci. 1991, 142, 149.

(20) Chapman, R. G.; Ostuni, E.; Takayama, S.; Holmlin, R. E.; Yan, L.; Whitesides, G. M. J. Am. Chem. Soc. 2000, 122, 8303.

(21) Holmlin, R. E.; Chen, X.; Chapman, R. G.; Takayama, S.; Whitesides, G. M. Langmuir 2001, 17, 2841.

(22) Jevševar, S.; Kunstelj, M.; Porekar, V. G. Biotechnol. J.: Healthcare Nutr. Technol. 2010, 5, 113.

(23) Kolate, A.; Baradia, D.; Patil, S.; Vhora, I.; Kore, G.; Misra, A. J. Controlled Release 2014, 192, 67.

(24) Zhang, P.; Sun, F.; Liu, S.; Jiang, S. J. Controlled Release 2016, 244, 184.

(25) Li, L.; Chen, S.; Jiang, S. J. Biomater. Sci., Polym. Ed. 2007, 18, 1415. 
(26) Bindra, D. S.; Williams, T. D.; Stella, V. J. Pharm. Res. 1994, 11, 1060.

(27) Hildebrandt, C.; Joos, L.; Saedler, R.; Winter, G. J. Pharm. Sci. 2015, 104, 1938.

(28) Hubbell, J. A. Curr. Opin. Biotechnol. 2003, 14, 551.

(29) Hayward, J. A.; Chapman, D. Biomaterials 1984, 5, 135.

(30) Leng, C.; Huang, H.; Zhang, K.; Hung, H.-C.; Xu, Y.; Li, Y.; Jiang, S.; Chen, Z. Langmuir 2018, 34, 6538.

(31) Laschewsky, A. Polymers (Basel) 2014, 6, 1544.

(32) Hess, M.; Jones, R. G.; Kahovec, J.; Kitayama, T.; Kratochvíl, P.; Kubisa, P.; Mormann, W.; Stepto, R. F. T.; Tabak, D.; Vohlídal, J.J. Macromol. Sci. Part A Pure Appl. Chem. 2006, 78, 2067.

(33) Mihara, S.; Yamaguchi, K.; Kobayashi, M. Langmuir 2019, 35 , 1172.

(34) Paschke, S.; Lienkamp, K. ACS Appl. Polym. Mater . 2020, 2, 129.

(35) Pradhan, S.; Kumar, S.; Mohanty, S.; Nayak, S. K. Polym.-Plast. Technol. Mater. 2019, 58, 498.

(36) Phiri, I.; Bon, C. Y.; Mwemezi, M.; Hamenu, L.; Madzvamuse, A.; Park, J. H.; Lee, K. S.; Ko, J. M.; Lu, Y. Mater. Chem. Phys. 2020, 243, 122577.

(37) Liu, Q.; Patel, A. A.; Liu, L. ACS Appl. Mater. Interfaces 2014, 6, 8996.

(38) Wei, T.; Tang, Z.; Yu, Q.; Chen, H. ACS Appl. Mater. Interfaces 2017, 9, 37511.

(39) Singha, P.; Locklin, J.; Handa, H. Acta Biomater. 2017, 50, 20.

(40) Mi, L.; Jiang, S. Angew. Chem. Int. Ed. Engl. 2014, 53, 1746.

(41) Li, X.; Wu, B.; Chen, H.; Nan, K.; Jin, Y.; Sun, L.; Wang, B. J. Mater. Chem. B 2018, 6, 4274.

(42) Campoccia, D.; Montanaro, L.; Arciola, C. R. Biomaterials 2013, $34,8533$.

(43) Ishihara, K. Trends Polym. Sci. 1997, 12, 401.

(44) Bain, C. D.; Whitesides, G. M. J. Am. Chem. Soc. 1988, 110, 5897.

(45) Storey, R.; Jones, R. G. W. Phytochemistry 1977, 16, 447.

(46) Ernst, R.; Miller, E. J. Surface-Active Betaines. In: Amphoteric Surfactants. Bluestein, B. R.; Hilton, C. L. Marcel Dekker: New York, 1982, 148-154.

(47) Lowe, A. B.; Vamvakaki, M.; Wassall, M. A.; Wong, L.; Billingham, N. C.; Armes, S. P.; Lloyd, A. W. J. Biomed. Mater. Res. 2000, 52, 88.

(48) Tuzar, Z.; Pospisil, H.; Plestil, J.; Lowe, A. B.; Baines, F. L.; Billingham, N. C.; Armes, S. P. Macromolecules 1997, 30, 2509.

(49) Lee, J. H.; Ju, Y. M.; Lee, W. K.; Park, K. D.; Kim, Y. H. J. Biomed. Mater. Res. 1998, 40, 314.

(50) Thompson, A. R.; Harker, L. A. Manual of Hemostasis and Thrombosis. FA Davis Company: Philadelphia, 1983.

(51) Yuan, Y. L.; Ai, F.; Zhang, J.; Zang, X. B.; Shen, J.; Lin, S. C. J. Biomater. Sci., Polym. Ed. 2002, 13, 1081.

(52) Yuan, Y.; Zhang, J.; Ai, F.; Yuan, J.; Zhou, J.; Shen, J.; Lin, S. Colloids Surf., B 2003, 29, 247.

(53) Chen, S.; Zheng, J.; Li, L.; Jiang, S. J. Am. Chem. Soc. 2005, 127, 14473.

(54) Zhang, Z.; Chao, T.; Chen, S.; Jiang, S. Langmuir 2006, 22, 10072.

(55) Li, Q.; Bi, Q.-Y.; Zhou, B.; Wang, X.-L. Appl. Surf. Sci. 2012, 258, 4707.

(56) Zhao, W.; Ye, Q.; Hu, H.; Wang, X.; Zhou, F. J. Mater. Chem. B 2014, 2, 5352.

(57) Zhang, J.; Yuan, J.; Yuan, Y.; Zang, X.; Shen, J.; Lin, S. Biomaterials 2003, 24, 4223.

(58) Kratzer, D.; Barner, L.; Friedmann, C.; Bräse, S.; Lahann, J. Eur. J. Org. Chem. 2014, 2014, 8064.

(59) Liu, Q.; Chiu, A.; Wang, L.; An, D.; Li, W.; Chen, E. Y.; Zhang, Y.; Pardo, Y.; McDonough, S. P.; Liu, L.; Liu, W. F.; Chen, J.; Ma, M. Biomaterials 2020, 230, 119640.
(60) Yuan, J.; Lin, S.; Shen, J. Colloids Surf., B 2008, 66, 90.

(61) Koc, J.; Schönemann, E.; Amuthalingam, A.; Clarke, J.; Finlay, J. A.; Clare, A. S.; Laschewsky, A.; Rosenhahn, A. Langmuir 2019, 35, 1552.

(62) Schönemann, E.; Koc, J.; Aldred, N.; Clare, A. S.; Laschewsky, A.; Rosenhahn, A.; Wischerhoff, E. Macromol. Rapid Commun. 2020, 41, 1900447.

(63) Hildebrand, V.; Laschewsky, A.; Päch, M.; Müller-Buschbaum, P.; Papadakis, C. M. Polym. Chem. 2017, 8, 310.

(64) Laschewsky, A.; Rosenhahn, A. Langmuir 2019, 35, 1056.

(65) Mo, F.; Ren, H.; Chen, S.; Ge, Z. Mater. Lett. 2015, 145, 174.

(66) Graiver, D.; Baer, E.; Litt, M.; Baney, R. H. J. Polym. Sci., Part A: Polym. Chem. 1979, 17, 3559.

(67) Zhu, Y.; Noy, J.-M.; Lowe, A. B.; Roth, P. J. Polym. Chem. 2015, 6, 5705.

(68) Fischer, R. F. Ind. Eng. Chem. 1964, 56, 41.

(69) Yuan, J.; Zhang, J.; Zhu, J.; Shen, J.; Lin, S. C.; Zhu, W.; Fang, J. L.J. Biomater. Appl. 2003, 18, 123.

(70) Yuan, J.; Zhu, J.; Zhu, C. H.; Shen, J.; Lin, S. C. Polym. Int. 2004, 53, 1722.

(71) Jiang, Y.; Qingfeng, H.; Baolei, L.; Jian, S.; Sicong, L. Colloids Surf., B 2004, 36, 19.

(72) Lowe, A. B.; Billingham, N. C.; Armes, S. P. Chem. Commun. 1996, 13, 1555.

(73) Abu-Thabit, N. Y.; Hamdy, A. S. Surf. Coat. Technol. 2016, 303, 406.

(74) Roy, S. G.; Banerjee, S.; De, P. Cationic Polymerization of Nonpolar Vinyl Monomers for Producing High Performance Polymers. In: Reference Module in Materials Science and Materials Engineering. Elsevier: Philadelphia, 2016.

(75) Minko, S. Grafting on Solid Surfaces: "Grafting To" and "grafting From" Methods. In: Polymer surfaces and interfaces. Stamm, M. Springer: Berlin, 2008, 215-234.

(76) Li, G.; Xue, H.; Cheng, G.; Chen, S.; Zhang, F.; Jiang, S. J. Phys. Chem. B 2008, 112, 15269.

(77) Matyjaszewski, K.; Xia, J. Chem. Rev. 2001, 101, 2921.

(78) Chang, Y.; Chang, Y.; Higuchi, A.; Shih, Y.-J.; Li, P.-T.; Chen, W.-Y.; Tsai, E.-M.; Hsiue, G.-H. Langmuir 2012, 28, 4309.

(79) Yu, B.-Y.; Zheng, J.; Chang, Y.; Sin, M.-C.; Chang, C.-H.; Higuchi, A.; Sun, Y.-M. Langmuir 2014, 30, 7502.

(80) Ippel, B. D.; Komil, M. I.; Bartels, P. A. A.; Söntjens, S. H. M.; Boonen, R. J. E. A.; Smulders, M. M. J.; Dankers, P. Y. W. Macromolecules 2020, 53, 4454.

(81) Yuan, Y. L.; Ai, F.; Zhang, J.; Zang, X. B.; Shen, J.; Lin, S. C. J. Biomater. Sci., Polym. Ed. 2002, 13, 1081.

(82) Shan, B.; Yan, H.; Shen, J.; Lin, S. J. Appl. Polym. Sci. 2006, 101, 3697.

(83) Chiang, Y.-C.; Chang, Y.; Higuchi, A.; Chen, W.-Y.; Ruaan, R.-C. J. Membr. Sci. 2009, 339, 151.

(84) Jun, Z.; Youling, Y.; Kehua, W.; Jian, S.; Sicong, L. Colloids Surf., $B$ 2003, 28, 1 .

(85) Yuan, Y.; Ai, F.; Zang, X.; Zhuang, W.; Shen, J.; Lin, S. Colloids Surf., B 2004, 35, 1.

(86) Jiang, Y.; Rongbing, B.; Ling, T.; Jian, S.; Sicong, L. Colloids Surf., $B$ 2004, 36, 27.

(87) Yuan, J.; Chen, L.; Jiang, X.; Shen, J.; Lin, S. Colloids Surf., B 2004, $39,87$.

(88) Wikberg, E.; Verhage, J. J.; Viklund, C.; Irgum, K. J. Sep. Sci. 2009, 32, 2008.

(89) Du, Y.; Gao, J.; Chen, T.; Zhang, C.; Ji, J.; Xu, Z.-K. Langmuir 2017, 33, 7298.

(90) Hanton, L. R.; Lee, K. J. Chem. Soc., Dalton Trans. 2000, 1161. 
(91) Cho, W. K.; Kong, B.; Choi, I. S. Langmuir 2007, 23, 5678.

(92) Fan, M.; Ma, Y.; Mao, J.; Zhang, Z.; Tan, H. Acta Biomater. 2015, $20,60$.

(93) Chou, Y.-N.; Wen, T.-C.; Chang, Y. Acta Biomater. 2016, 40, 78.

(94) Kwon, H. J.; Lee, Y.; Phuong, L. T.; Seon, G. M.; Kim, E.; Park, J. C.; Yoon, H.; Park, K. D. Acta Biomater. 2017, 61, 169.

(95) Chien, H.-W.; Tsai, C.-C.; Tsai, W.-B.; Wang, M.-J.; Kuo, W.-H.; Wei, T.-C.; Huang, S.-T. Colloids Surf., B 2013, 107, 152.

(96) Lee, H.; Dellatore, S. M.; Miller, W. M.; Messersmith, P. B. Science 2007, 318, 426.

(97) Dreyer, D. R.; Miller, D. J.; Freeman, B. D.; Paul, D. R.; Bielawski, C. W. Langmuir 2012, 28, 6428.

(98) Yesilyurt, V.; Veiseh, O.; Doloff, J. C.; Li, J.; Bose, S.; Xie, X.; Bader, A. R.; Chen, M.; Webber, M. J.; Vegas, A. J.; Langer, R.; Anderson, D. G. Adv. Healthcare Mater. 2017, 6, 1601091.

(99) Dizon, G. V.; Chou, Y.-N.; Yeh, L.-C.; Venault, A.; Huang, J.; Chang, Y. J. Colloid Interface Sci. 2018, 529, 77.

(100) Li, G.; Cheng, G.; Xue, H.; Chen, S.; Zhang, F.; Jiang, S. Biomaterials 2008, 29, 4592.

(101) Huang, J.; Xu, W. J. Appl. Polym. Sci. 2011, 122, 1251.

(102) Chien, H.-W.; Keng, M.-C.; Chen, H.-Y.; Huang, S.-T.; Tsai, W.-B. Biomater. Biomech. Bioeng. 2016, 3, 59.

(103) Estephan, Z. G.; Jaber, J. A.; Schlenoff, J. B. Langmuir 2010, 26, 16884.

(104) Knowles, B. R.; Wagner, P.; Maclaughlin, S.; Higgins, M. J.; Molino, P. J. ACS Appl. Mater. Interfaces 2017, 9, 18584.

(105) Hammond, P. T. Mater. Today 2012, 15, 196.

(106) Kuo, W.-H.; Wang, M.-J.; Chien, H.-W.; Wei, T.-C.; Lee, C.; Tsai, W.-B. Biomacromolecules 2011, 12, 4348.

(107) O'Brien, P. Chemical Vapor Deposition. In: Encyclopedia of Materials: Science and Technology. Buschow, K. H. J.; Cahn, R. W.; Flemings, M. C.; Ilschner, B.; Kramer, E. J.; Mahajan, S.; Veyssière, P. Elsevier: Oxford, 2001, 1173-1176.

(108) Brown, R. H.; Hunley, M. T.; Allen, M. H.; Long, T. E. Polymer (Guildf.) 2009, 50, 4781.

(109) Yang, W.; Sundaram, H. S.; Ella, J.-R.; He, N.; Jiang, S. Acta Biomater. 2016, 40, 92.

(110) Venault, A.; Chang, Y.; Yang, H.-S.; Lin, P.-Y.; Shih, Y.-J.; Higuchi, A. J. Membr. Sci. 2014, 454, 253.

(111) Chang, Y.; Chen, S.; Zhang, Z.; Jiang, S. Langmuir 2006, 22, 2222.

(112) Zhou, Q.; Lei, X.-P.; Li, J.-H.; Yan, B.-F.; Zhang, Q.-Q. Desalination 2014, 337, 6 .

(113) Chen, S.-H.; Chang, Y.; Lee, K.-R.; Wei, T.-C.; Higuchi, A.; Ho, F.-M.; Tsou, C.-C.; Ho, H.-T.; Lai, J.-Y. Langmuir 2012, 28, 17733.

(114) Zhao, J.; Shi, Q.; Luan, S.; Song, L.; Yang, H.; Shi, H.; Jin, J.; Li, X.; Yin, J.; Stagnaro, P. J. Membr. Sci. 2011, 369, 5.

(115) An, Y.; Wang, Z.; Wu, Z.; Yang, D.; Zhou, Q. Chem. Eng. J. 2009, $155,709$.

(116) Jhaveri, J. H.; Murthy, Z. V. P. Desalination 2016, 379, 137.

(117) Ayyavoo, J.; Nguyen, T. P. N.; Jun, B.-M.; Kim, I.-C.; Kwon, Y.-N. Colloids Surf., A 2016, 506, 190.

(118) Dizon, G. V.; Venault, A. J. Membr. Sci. 2018, 550, 45.

(119) Zhang, Y.; Wang, Z.; Lin, W.; Sun, H.; Wu, L.; Chen, S. J. Membr. Sci. 2013, 446, 164.

(120) Zhou, M.; Liu, H.; Kilduff, J. E.; Langer, R.; Anderson, D. G.; Belfort, G. Environ. Sci. Technol. 2009, 43, 3865.

(121) Zhao, Y.-H.; Wee, K.-H.; Bai, R. J. Membr. Sci. 2010, 362, 326.

(122) Zhao, Y.-H.; Wee, K.-H.; Bai, R. ACS Appl. Mater. Interfaces 2010, $2,203$.

(123) Li, M.-Z.; Li, J.-H.; Shao, X.-S.; Miao, J.; Wang, J.-B.; Zhang, Q.-Q.; Xu, X.-P. J. Membr. Sci. 2012, 405, 141.
(124) Thankappan, H.; Bousquet, G.; Semsarilar, M.; Venault, A.; Chang, Y.; Bouyer, D.; Quemener, D. Membranes 2019, 9, 93.

(125) Li, J.-H.; Li, M.-Z.; Miao, J.; Wang, J.-B.; Shao, X.-S.; Zhang, Q.-Q. Appl. Surf. Sci. 2012, 258, 6398.

(126) Ang, W. S.; Elimelech, M. J. Membr. Sci. 2007, 296, 83.

(127) Jarusutthirak, C.; Amy, G.; Croué, J.-P. Desalination 2002, 145, 247.

(128) Hothi, D. K.; Geary, D. F. Pediatric Hemodialysis Prescription, Efficacy, and Outcome. In: Comprehensive Pediatric Nephrology. Geary, D. F.; Schaefer, F. Mosby: Philadelphia, 2008, 867-893.

(129) Yuan, J.; Zhang, J.; Zang, X.; Shen, J.; Lin, S. Colloids Surf., B 2003, $30,147$.

(130) Liu, P.-S.; Chen, Q.; Liu, X.; Yuan, B.; Wu, S.-S.; Shen, J.; Lin, S.-C. Biomacromolecules 2009, 10, 2809.

(131) Tolwani, A. J.; Connor, M. J.; Palevsky, P. M. Renal Replacement Therapy for Acute Kidney Injury. In: Chronic Kidney Disease, Dialysis, and Transplantation (Fourth Edition). Himmelfarb, J.; Ikizler, T. A. Elsevier: Philadelphia, 2019, 739-753.e8.

(132) Carpenter, A. W.; de Lannoy, C.-F.; Wiesner, M. R. Environ. Sci. Technol. 2015, 49, 5277.

(133) Jhong, J.-F.; Venault, A.; Hou, C.-C.; Chen, S.-H.; Wei, T.-C.; Zheng, J.; Huang, J.; Chang, Y. ACS Appl. Mater. Interfaces 2013, $5,6732$.

(134) Lin, H.-T.; Venault, A.; Chang, Y. J. Membr. Sci. 2019, 591, 117319.

(135) Wu, J.; Xiao, Z.; Chen, A.; He, H.; He, C.; Shuai, X.; Li, X.; Chen, S.; Zhang, Y.; Ren, B.; Zheng, J.; Xiao, J. Acta Biomater. 2018, 71, 293.

(136) He, H.; Xiao, Z.; Zhou, Y.; Chen, A.; Xuan, X.; Li, Y.; Guo, X.; Zheng, J.; Xiao, J.; Wu, J. J. Mater. Chem. B 2019, 7, 1697.

(137) Ruseva, K.; Ivanova, K.; Todorova, K.; Gabrashanska, M.; Hinojosa-Caballero, D.; Tzanov, T.; Vassileva, E. Eur. Polym. J. 2019, 117, 391.

(138) Xie, J.; Xu, C.; Kohler, N.; Hou, Y.; Sun, S. Adv. Mater. 2007, 19, 3163.

(139) Elsabahy, M.; Wooley, K. L. Chem. Soc. Rev. 2012, 41, 2545.

(140) Wilhelm, S.; Tavares, A. J.; Dai, Q.; Ohta, S.; Audet, J.; Dvorak, H. F.; Chan, W. C. W. Nat. Rev. Mater. 2016, 1, 1.

(141) García, K. P.; Zarschler, K.; Barbaro, L.; Barreto, J. A.; O'Malley, W.; Spiccia, L.; Stephan, H.; Graham, B. Small 2014, 10, 2516.

(142) Jin, Q.; Chen, Y.; Wang, Y.; Ji, J. Colloids Surf., B 2014, 124, 80.

(143) Fam, S. Y.; Chee, C. F.; Yong, C. Y.; Ho, K. L.; Mariatulqabtiah, A. R.; Tan, W. S. Nanomaterials 2020, 10, E787.

(144) Rouhana, L. L.; Jaber, J. A.; Schlenoff, J. B. Langmuir 2007, 23, 12799.

(145) Li, H.; Han, J.; Liang, G. ACS Applied Nano Mater. 2020, 3, 1489.

(146) van Andel, E.; de Bus, I.; Tijhaar, E. J.; Smulders, M. M. J.; Savelkoul, H. F. J.; Zuilhof, H. ACS Appl. Mater. Interfaces 2017, 9, 38211.

(147) Xiao, Y.; Du, J. J. Mater. Chem. B 2020, 8, 354.

(148) Chouly, C.; Pouliquen, D.; Lucet, I.; Jeune, J. J.; Jallet, P. J. Microencapsulation 1996, 13, 245.

(149) Meng, J.; Xiao, B.; Zhang, Y.; Liu, J.; Xue, H.; Lei, J.; Kong, H.; Huang, Y.; Jin, Z.; Gu, N.; Xu, H. Sci. Rep. 2013, 3, 2655.

(150) Estephan, Z. G.; Hariri, H. H.; Schlenoff, J. B. Langmuir 2013, 29, 2572.

(151) Wei, H.; Insin, N.; Lee, J.; Han, H.-S.; Cordero, J. M.; Liu, W.; Bawendi, M. G. Nano Lett. 2012, 12, 22.

(152) Zhou, Z.; Wang, L.; Chi, X.; Bao, J.; Yang, L.; Zhao, W.; Chen, Z.; Wang, X.; Chen, X.; Gao, J. ACS Nano 2013, 7, 3287. 
(153) Peng, S.; Ouyang, B.; Men, Y.; Du, Y.; Cao, Y.; Xie, R.; Pang, Z.; Shen, S.; Yang, W. Biomaterials 2020, 231, 119680.

(154) Schlorf, T.; Meincke, M.; Kossel, E.; Glüer, C.-C.; Jansen, O.; Mentlein, R. Int. J. Mol. Sci. 2010, 12, 12.

(155) Knowles, B. R.; Yang, D.; Wagner, P.; Maclaughlin, S.; Higgins, M. J.; Molino, P. J. Langmuir 2019, 35, 1335.

(156) Knowles, B. R.; Wagner, P.; Maclaughlin, S.; Higgins, M. J.; Molino, P. J. Biointerphases 2020, 15, 021009.

(157) Kairdolf, B. A.; Smith, A. M.; Stokes, T. H.; Wang, M. D.; Young, A. N.; Nie, S. Annu. Rev. Anal. Chem. 2013, 6, 143.

(158) Sun, M.; Hoffman, D.; Sundaresan, G.; Yang, L.; Lamichhane, N.; Zweit, J. Am. J. Nucl. Med. Mol. Imaging 2012, 2, 122.

(159) Muro, E.; Fragola, A.; Pons, T.; Lequeux, N.; Ioannou, A.; Skourides, P.; Dubertret, B. Small 2012, 8, 1029.

(160) Muro, E.; Pons, T.; Lequeux, N.; Fragola, A.; Sanson, N.; Lenkei, Z.; Dubertret, B. J. Am. Chem. Soc. 2010, 132, 4556.

(161) Deng, T.; Peng, Y.; Zhang, R.; Wang, J.; Zhang, J.; Gu, Y.; Huang, D.; Deng, D. ACS Appl. Mater. Interfaces 2017, 9, 11405.

(162) Giovanelli, E.; Muro, E.; Sitbon, G.; Hanafi, M.; Pons, T.; Dubertret, B.; Lequeux, N. Langmuir 2012, 28, 15177.

(163) Zhan, N.; Palui, G.; Safi, M.; Ji, X.; Mattoussi, H.J. Am. Chem. Soc. 2013, 135, 13786.

(164) Susumu, K.; Oh, E.; Delehanty, J. B.; Blanco-Canosa, J. B.; Johnson, B. J.; Jain, V.; Hervey, W. J. IV; Algar, W. R.; Boeneman, K.; Dawson, P. E.; Medintz, I. L. J. Am. Chem. Soc. 2011, 133, 9480.

(165) Park, J.; Nam, J.; Won, N.; Jin, H.; Jung, S.; Jung, S.; Cho, S.; Kim, S. Adv. Funct. Mater. 2011, 21, 1558.

(166) Tasso, M.; Giovanelli, E.; Zala, D.; Bouccara, S.; Fragola, A.; Hanafi, M.; Lenkei, Z.; Pons, T.; Lequeux, N. ACS Nano 2015, 9, 11479.

(167) Debayle, M.; Marchandier, T.; Xu, X.; Lequeux, N.; Pons, T. ACS Appl. Mater. Interfaces 2019, 11, 25008.

(168) Trapiella-Alfonso, L.; Pons, T.; Lequeux, N.; Leleu, L.; Grimaldi, J.; Tasso, M.; Oujagir, E.; Seguin, J.; d'Orlyé, F.; Girard, C.; Doan, B.-T.; Varenne, A. ACS Appl. Mater. Interfaces 2018, 10, 17107.

(169) Mangeolle, T.; Yakavets, I.; Lequeux, N.; Pons, T.; Bezdetnaya, L.; Marchal, F. Photodiagn. Photodyn. Ther. 2019, 26, 150.

(170) Baggerman, J.; Smulders, M. M. J.; Zuilhof, H. Langmuir 2019, $35,1072$.

(171) Kitano, H.; Suzuki, H.; Matsuura, K.; Ohno, K. Langmuir 2010 , $26,6767$.

(172) Li, Y.; Giesbers, M.; Gerth, M.; Zuilhof, H. Langmuir 2012, 28, 12509.

(173) Robinson, K. J.; Coffey, J. W.; Muller, D. A.; Young, P. R.; Kendall, M. A. F.; Thurecht, K. J.; Grøndahl, L.; Corrie, S. R. Biointerphases 2015, 10, 04A305.

(174) Kim, G.; Yong, Y.; Kang, H. J.; Park, K.; Kim, S. I.; Lee, M.; Huh, N. Biomaterials 2014, 35, 294.

(175) Cao, J.; Xiu, K.-M.; Zhu, K.; Chen, Y.-W.; Luo, X.-L. J. Biomed. Mater. Res. Part A 2012, 100, 2079.

(176) Cao, J.; Lu, A.; Li, C.; Cai, M.; Chen, Y.; Li, S.; Luo, X. Colloids Surf., B 2013, 112, 35.

(177) Cao, J.; Xie, X.; Lu, A.; He, B.; Chen, Y.; Gu, Z.; Luo, X. Biomaterials 2014, 35, 4517.

(178) Wu, Z.; Cai, M.; Xie, X.; He, L.; Huang, L.; Chen, Y.; Luo, X. RSC Adv. 2015, 5, 106989.

(179) Xie, X.; Ma, Y.; Huang, L.; Cai, M.; Chen, Y.; Luo, X. Colloids Surf., A 2015, 468, 31 .

(180) Zhai, S.; Ma, Y.; Chen, Y.; Li, D.; Cao, J.; Liu, Y.; Cai, M.; Xie, X.; Chen, Y.; Luo, X. Polym. Chem. 2014, 5, 1285.
(181) Cai, M.; Leng, M.; Lu, A.; He, L.; Xie, X.; Huang, L.; Ma, Y.; Cao, J.; Chen, Y.; Luo, X. Colloids Surf., B 2015, 126, 1.

(182) Dai, F.; Wang, P.; Wang, Y.; Tang, L.; Yang, J.; Liu, W.; Li, H.; Wang, G. Polymer (Guildf.. 2008, 49, 5322.

(183) Shih, Y.; Venault, A.; Tayo, L. L.; Chen, S.-H.; Higuchi, A.; Deratani, A.; Chinnathambi, A.; Alharbi, S. A.; Quemener, D.; Chang, Y. Langmuir 2017, 33, 1914.

(184) Wang, W.; Nan, W.; Sun, L.; Liu, W. React. Funct. Polym. 2013, 73, 993.

(185) Dai, F.; Liu, Y.; Wang, W.; Liu, W. J. Biomater. Sci., Polym. Ed. 2013, 24, 330.

(186) Zhai, X.; Wang, W.; Wang, C.; Wang, Q.; Liu, W. J. Mater. Chem. 2012, 22, 23576.

(187) Hoffman, A. S. Adv. Drug Delivery Rev. 2012, 64, 18.

(188) Mantooth, S. M.; Munoz-Robles, B. G.; Webber, M. J. Macromol. Biosci. 2019, 19, e1800281.

(189) Carr, L.; Cheng, G.; Xue, H.; Jiang, S. Langmuir 2010, 26, 14793.

(190) Zhang, Z.; Chao, T.; Jiang, S. J. Phys. Chem. B 2008, 112, 5327.

(191) Kasák, P.; Kroneková, Z.; Krupa, I.; Lacík, I. Polymer (Guildf.. 2011, 52, 3011.

(192) Ning, J.; Kubota, K.; Li, G.; Haraguchi, K. React. Funct. Polym. 2013, 73, 969.

(193) Zhang, Z.; Chao, T.; Liu, L.; Cheng, G.; Ratner, B. D.; Jiang, S. J. Biomater. Sci., Polym. Ed. 2009, 20, 1845.

(194) Venault, A.; Huang, C.-W.; Zheng, J.; Chinnathambi, A.; Alharbi, S. A.; Chang, Y.; Chang, Y. Int. J. Polym. Mater. Polym. Biomater. 2016, 65, 65.

(195) Chang, Y.; Yandi, W.; Chen, W.-Y.; Shih, Y.-J.; Yang, C.-C.; Chang, Y.; Ling, Q.-D.; Higuchi, A. Biomacromolecules 2010, 11, 1101.

(196) Susanto, H.; Ulbricht, M. Langmuir 2007, 23, 7818.

(197) Kasák, P.; Mosnáček, J.; Danko, M.; Krupa, I.; Hloušková, G.; Chorvát, D.; Koukaki, M.; Karamanou, S.; Economou, A.; Lacík, I. RSC Adv. 2016, 6, 83890.

(198) Ning, J.; Li, G.; Haraguchi, K. Macromolecules 2013, 46, 5317.

(199) Ning, J.; Li, G.; Haraguchi, K. Macromol. Chem. Phys. 2014, 215, 235.

(200) Haraguchi, K.; Ning, J.; Li, G. Eur. Polym. J. 2015, 68, 630.

(201) Liu, Q.; Chiu, A.; Wang, L.-H.; An, D.; Zhong, M.; Smink, A. M.; de Haan, B. J.; de Vos, P.; Keane, K.; Vegge, A.; Chen, E. Y.; Song, W.; Liu, W. F.; Flanders, J.; Rescan, C.; Grunnet, L. G.; Wang, X.; Ma, M. Nat. Commun. 2019, 10, 5262.

(202) Yong, Y.; Qiao, M.; Chiu, A.; Fuchs, S.; Liu, Q.; Pardo, Y.; Worobo, R.; Liu, Z.; Ma, M. Langmuir 2019, 35, 1927.

(203) Ladd, J.; Zhang, Z.; Chen, S.; Hower, J. C.; Jiang, S. Biomacromolecules 2008, 9, 1357.

(204) Emmenegger, C. R.; Rodriguez Emmenegger, C.; Brynda, E.; Riedel, T.; Sedlakova, Z.; Houska, M.; Bologna Alles, A. Langmuir 2009, 25, 6328.

(205) Danko, M.; Kroneková, Z.; Mrlik, M.; Osicka, J.; Bin Yousaf, A.; Mihálová, A.; Tkac, J.; Kasak, P. Langmuir 2019, 35, 1391.

(206) Zhang, Z.; Chen, S.; Jiang, S. Biomacromolecules 2006, 7, 3311.

(207) Izumrudov, V. A.; Zelikin, A. N.; Zhiryakova, M. V.; Jaeger, W.; Bohrisch, J. J. Phys. Chem. B 2003, 107, 7982.

(208) Wu, L.; Jasinski, J.; Krishnan, S. J. Appl. Polym. Sci. 2012, 124, 2154.

(209) Lim, J.; Matsuoka, H.; Saruwatari, Y. Langmuir 2020, 36, 1727.

(210) McPherson, T.; Kidane, A.; Szleifer, I.; Park, K. Langmuir 1998, 14, 176. 
(211) van Andel, E.; Lange, S. C.; Pujari, S. P.; Tijhaar, E. J.; Smulders, M. M. J.; Savelkoul, H. F. J.; Zuilhof, H. Langmuir 2019, 35, 1181.

(212) Kisley, L.; Miller, K. A.; Davis, C. M.; Guin, D.; Murphy, E. A.; Gruebele, M.; Leckband, D. E. Biomacromolecules 2018, 19, 3894

(213) Iqbal, Z.; Moses, W.; Kim, S.; Kim, E. J.; Fissell, W. H.; Roy, S. J. Biomed. Mater. Res. Part B 2018, 106, 2327.
(214) Iqbal, Z.; Kim, S.; Moyer, J.; Moses, W.; Abada, E.; Wright, N.; Kim, E. J.; Park, J.; Fissell, W. H.; Vartanian, S.; Roy, S. J. Biomater. Appl. 2019, 34, 297.

(215) Chen, X.; Yang, D. Biomater. Sci. 2020, 8, 4906.

(216) Lichtenberg, J. Y.; Ling, Y.; Kim, S. Sensors 2019, 19 E2488.

(217) Feiner, R.; Dvir, T. Nat. Rev. Mater. 2018, 3, 17076. 